As always when using mortality data, one must consider the quality of the diagnosis from which the death rates are obtained. Though it is known that there are errors, and that changes in accuracy take place over time, the effect of these was reduced in our analysis by limiting the data to mortality among persons under 70 , dying since 1950 . Mortality reflects the balance of incidence and case fatality, and trends should be interpreted with this in mind. The absence of any substantial period of death effects for three of the five cancers discussed should not therefore be taken as indicative necessarily of the lack of improvement in treatment over the years.

A complete description of trends for all sites of cancer for which suitable mortality rates are available is being prepared and will be published elsewhere.

We are grateful to Dr A M Adelstein and W R Gilks for helpful discussions.

\section{References}

1 Doll R, Peto R. The causes of cancer: quantitative estimates of avoidable risks of cancer in the United States today. Fournal of the National Cancer Institute $1981 ; 66: 1192-1308$.

2 Peto R. Distorting the epidemiology of cancer: the need for a more balanced overview. Nature 1980;284:297-300.

Epstein SS, Swartz JB. Fallacies of lifestyle cancer theories. Nature 1981; 289:127-30.

- Office of Population Censuses and Surveys. Cancer mortality, England and Wales, 1911-1970. London: HMSO, 1975. (Studies on medical and population subjects, No 29.)

5 Office of Population Censuses and Surveys. Cancer mortality in England and Wales, 1971-1978. London: HMSO, 1980. (OPCS monitor, DH1 $80 / 3$.
6 Office of Population Censuses and Surveys. Mortality statistics. Cause. London: HMSO, 1980. (OPCS series DH2, No 6.)

${ }^{7}$ Office of Population Censuses and Surveys. Mortality statistics. Cause. London: HMSO, 1981. (OPCS series DH2, No 7.)

8 Barrett JC. Age, time and cohort factors in mortality from cancer of the cervix. Fournal of Hygiene (Cambridge) 1973;71:253-9.

- Kermack WO, McKendrick AG, McKinlay PL. Death rates in Great Britain and Sweden: expression of specific mortality rates as products of two factors and some consequences thereof. $\mathcal{F}$ Hygiene (Cambridge) 1934; 34:433-57.

${ }^{10}$ Nordling $\mathrm{CO}$. A new theory of the cancer inducing mechanism. $\mathrm{Br} \mathfrak{F}$ Cancer 1953;7:68-72.

11 Doll R. The age distribution of cancer: implications for models of carcinogenesis. Fournal of the Royal Statistical Society (Series A) 1971 ;134:13366.

12 Case RAM, Hosker ME, McDonald DB, Pearson JT. Tumours of the urinary bladder in workmen engaged in the manufacture and use of certain dyestuff intermediates in the British chemical industry. $\mathrm{Br} \mathcal{F}$ Ind Med $1954 ; 11: 75-104$

${ }^{13}$ Chilvers C, Fraser P, Beral V. Alcohol and oesophageal cancer : an assessment of the evidence from routinely collected data. $\mathcal{F}$ Epidemiol Community Health $1979 ; 33: 127-33$

14 Davies JM. Testicular cancer in England and Wales : some epidemiological aspects. Lancet $1981 ; \mathrm{i}: 928-31$.

15 Lee PN, ed. Statistics of smoking in the United Kingdom. Research paper I. 7th ed. London: Tobacco Research Council, 1976.

16 Wald N, Doll R, Copeland G. Trends in tar, nicotine and carbon monoxide yields of UK cigarettes manufactured since 1934. Br Med f 1981;282: 763-5.

17 Todd GF, Lee PN, Wilson MJ. Cohort analysis of cigarette smoking and of mortality from four associated diseases. Occasional paper, No 3. London: Tobacco Research Council, 1976.

18 Adelstein AM. Encouragement from recent statistics. In : Raven RW, ed. Outlook on cancer. New York and London: Plenum Press, 1977.

19 Beral V. Cancer of the cervix: a sexually transmitted infection? Lancet 1974 ; : :1037-9.

(Accepted 2 February 1982)

\title{
Short-term prophylaxis with cefotaxime for prostatic surgery
}

\author{
T B HARGREAVE, J R HINDMARSH， R ELTON， G D CHISHOLM，J C GOULD
}

\begin{abstract}
A randomised controlled trial of a new cephalosporin, cefotaxime, was carried out in men undergoing transurethral resection of the prostate. The purpose of the trial was to determine whether 48-hour prophylaxis with this new broad-spectrum, non-nephrotoxic cephalosporin would reduce postoperative bacteriuria and postoperative complications. The treated patients fared significantly better than the non-treated patients in having fewer febrile episodes, fewer episodes of tachycardia, a lower incidence of appreciable bacteriuria
\end{abstract}

\footnotetext{
University Department of Surgery and Urology, Western General Hospital, Edinburgh

T B HARGREAVE, MB, FRCS, senior lecturer and honorary consultant urologist

J R HINDMARSH, MD, FRCS, senior registrar (now senior lecturer, Institute of Urology, London)

G D CHISHOLM, CHM, FRCS, professor of surgery and honorary consultant urologist

Department of Medical Computing and Statistics, Edinburgh University

R ELTON, BA, PHD, lecturer

Microbiology Department, Western General Hospital, Edinburgh
} J C GOULD, MD, FRCPATH, consultant bacteriologist postoperatively, and fewer complications, and spending on average one day less in hospital. There was no difference in postoperative urea and creatinine concentrations between the groups, and no other side effects of cefotaxime occurred in this elderly population.

Prophylaxis with cefotaxime would appear to make prostatic surgery safer.

\section{Introduction}

A 40-year-old man has been estimated to have a $10 \%$ chance of requiring prostatectomy by the age of $80 . .^{1}$ Thus prostatectomy remains one of the most frequently performed operations. In recent years there has been a change in technique so that most prostatectomy operations are by transurethral resection. This has occurred because of the lower mortality and morbidity associated with transurethral surgery. ${ }^{2}$ Nevertheless, complications still occur and any treatment or variation in technique that will make this operation safer is to be welcomed.

In a previous study a 48-hour regimen of antibiotic prophylaxis with cephradine resulted in a statistically significant reduction in postoperative bacteriuria and a possible but not statistically significant reduction in postoperative complications. ${ }^{3}$ We undertook the present trial to determine whether by using the new parenteral cephalosporin cefotaxime, which has a greater 
spectrum of activity than cephradine, we would reduce postoperative complications. Cefotaxime is more active than cefuroxime and cefoxitin against Gram-negative bacteria as well as being four times as active in vitro as carbenicillin against Pseudomonas aeruginosa strains. ${ }^{4}$ Cefotaxime is well tolerated by the kidney ${ }^{5}{ }^{6}$ and so would be particularly useful in an elderly population, in whom renal function may not always be optimal. Throughout the trial particular note was made of any complications that might be attributable to this new antibiotic.

\section{Patients and methods}

All patients undergoing transurethral prostatic surgery were eligible for this trial, but we excluded those known to have hypersensitivity to penicillins or cephalosporins, with a serum creatinine concentration of over $0.2 \mathrm{mmol} / 1(2.3 \mathrm{mg} / 100 \mathrm{ml})$, with known preoperative urinary infection, or already taking antibiotics. In many cases, however, the patient had considerable bacteriuria at the time of operation but this was not known until afterwards. We included these patients in the analysis because it is important to know the effect of prophylactic regimens in such cases, which are common. All patients gave informed consent to participate in the trial.

The patients were stratified into two groups-namely, those with a preoperative catheter and those without. Within each group cefotaxime or no treatment was given according to a randomisation scheme. Cefotaxime $500 \mathrm{mg}$ was given intravenously with the induction of anaesthesia and then intramuscularly every 12 hours to give a total of $2 \mathrm{~g}$ over 48 hours. Although the technique was standardised, the operations were performed by different surgeons. The resectoscope was lubricated with K-Y Jelly, and during the procedure glycine was used to irrigate the bladder. At the end of the resection a three-way Foley catheter was introduced and continuous irrigation with physiological saline used until haemostasis was sufficient to ensure free flow of urine. Additional bladder irrigations were undertaken only when required, and sterile water was used. No additional antibacterial agents were used. Catheters were removed as soon as signs of fresh bleeding had stopped.

Data on clinical progress were recorded daily. Recatheterisation was necessary when a patient could not void either after removal of the catheter or when a catheter had become blocked by blood clots. Continence problems referred to temporary incontinence of more than 24 hours' duration after removal of the urethral catheter, and dysuria was recorded only if symptoms persisted for more than 24 hours after removal of the catheter. Urine samples were examined daily from the day of admission until discharge or 10 days postoperatively. Either a midstream specimen or, if the patient had a catheter, a specimen aspirated from the tubing was examined. Samples were specially identified and handled separately and blind by the hospital bacteriology department. Appreciable bacteriuria was defined as $10^{5}$ or more organisms/ $\mathrm{ml}$ of urine. Blood samples were taken for estimation of haemoglobin, urea, and electrolyte concentrations before operation and between the fourth and seventh postoperative days.

Statistical analyses of treatment differences for all patients were carried out using $\chi^{2}$ tests or Wilcoxon rank sum tests as appropriate. Multiple logistic regression was used within subgroups of patients to evaluate treatment effects on binary response variables; a nonsignificant interaction between treatment and subgroup on the logistic scale was interpreted as indicating no difference in the efficacy of the treatment between subgroups.

\section{Results}

Altogether 239 patients entered the trial. The groups were well balanced with respect to number of patients, age, and results of haematological and biochemical investigations. Other factors (table I) also occurred in similar proportions of patients in the two groups.

TABLE I-Details of the two treatment groups

\begin{tabular}{lcc}
\hline & Cefotaxime & No treatment \\
\hline No of patients & 120 & 119 \\
No with catheter & 23 & 24 \\
No ( ${ }^{\circ}$ () with unknown preoperative bacteriuria & $14(12)$ & $13(12)$ \\
Mean weight of prostate resected (g) & 14.9 & 16.6 \\
No of patients with carcinoma of prostate & 15 & 11 \\
\hline
\end{tabular}

Patients treated with cefotaxime showed significant reductions in the mean duration of stay in hospital, episodes of high fever and tachycardia, and overall incidence of postoperative complications (table II). Table III shows the nature and incidences of the various complications. The absence of postoperative rigor in patients receiving cefotaxime is noteworthy, as is the decreased need for recatheterisation and the lower incidence of continence problems.

Table IV gives details of postoperative bacteriuria. Significantly fewer infections occurred in the treated group. When the infections were classified according to organism this trend was consistent. The difference between the two groups in the incidence of infection caused by Streptococcus faecalis achieved significance.

TABLE II-Results of clinical assessments

\begin{tabular}{|c|c|c|c|}
\hline & Cefotaxime & No treatment & Significance \\
\hline $\begin{array}{l}\text { Mean stay in hospital (days) } \\
\text { No (") of patients with temperature }\end{array}$ & $4 \cdot 3$ & $5 \cdot 3$ & $\mathrm{p}<0.01$ \\
\hline $\begin{array}{l}>38 \mathrm{C} \text { at any time } \\
\text { Mean maximum temperature }(\mathrm{C}) \\
\text { No of patients with pulse }>90 / \mathrm{min}\end{array}$ & $\begin{array}{c}3(3) \\
37 \cdot 2\end{array}$ & $\begin{array}{l}11(9) \\
37 \cdot 4\end{array}$ & $\begin{array}{l}\mathrm{p}<0.05 \\
\mathrm{p}<0.05\end{array}$ \\
\hline $\begin{array}{l}\text { at any time } \\
\text { Mean maximum pulse (beats } / \mathrm{min}) \\
\text { No }\left({ }^{\circ}\right) \text { of patients with any complication }\end{array}$ & $\begin{array}{l}23(19) \\
84 \cdot 5 \\
36(30)\end{array}$ & $\begin{array}{l}43(36) \\
89 \cdot 01 \\
61(51)\end{array}$ & $\begin{array}{l}\mathbf{p}<0.01 \\
\mathbf{p}<0.001 \\
\mathbf{p}<0.01\end{array}$ \\
\hline
\end{tabular}

TABLE III-Details of postoperative complications (some patients had more than one complication). Figures are numbers $(\%)$ of patients

\begin{tabular}{lcc}
\hline & Cefotaxime & No treatment \\
\hline Bacteraemia & 1 & 1 \\
Rigor & 1 & $6(5)$ \\
Sweating attacks & 2 & 1 \\
Postoperative hypotension & $7(6)$ & $11(9)$ \\
Haematuria & $4(3)$ & $9(8)$ \\
Orchitis & $19(16)$ & $20(17)$ \\
Frequency/dysuria/urgency & 1 & 2 \\
Continence problems & $5(4)$ & $12(10)$ \\
Bypassing catheter & 4 & 2 \\
Recatheterisation & 1 & 4 \\
Cousea and vomiting & 1 & 1 \\
Diarripation & 1 & $5(4)$ \\
Headache & 1 & \\
Backache & 1 & 1 \\
Rectal pain & 1 & 3 \\
Thigh pain & & 3 \\
Lesions at injection site & & 1 \\
Urticarial rash & & 1 \\
Chest infection & & 1 \\
Confusion & & \\
Ferebrovascular aver & & \\
Nocturnal dyspnoea & 1 & \\
Passed a stone & &
\end{tabular}

TABLE IV-Bacteriological results. (Figures are numbers (\%) of patients)

\begin{tabular}{lccc}
\hline & Cefotaxime & No treatment & Significance \\
\hline Appreciable bacteriuria $\left(>10^{5}\right.$ & $12(10)$ & $31(26)$ & $\mathrm{p}<0.01$ \\
organisms/ml) & $9(8)$ & $15(13)$ & $\mathrm{NS}$ \\
Escherichia coli & $1(1)$ & $3(3)$ & $\mathrm{NS}$ \\
$\begin{array}{l}\text { Proteus } \\
\text { Pseudomonas }\end{array}$ & $2(2)$ & $2(2)$ & $\mathrm{NS}$ \\
$\begin{array}{l}\text { Streptococcus faecalis } \\
\text { Staphylococcus }\end{array}$ & $2(2)$ & $7(8)$ & $\mathrm{p}<0.01$ \\
$\begin{array}{l}\text { Microbacterium } \\
\text { Another antibiotic used }\end{array}$ & & $1(6)$ & $\mathrm{NS}$ \\
postoperatively & $1(1)$ & $23(19)$ & $\mathrm{NS}$ \\
& & & $\mathrm{p}<0.001$ \\
\hline
\end{tabular}

In addition to analysing the overall results we also analysed whether cefotaxime was equally effective in the following subgroups: patients with and without a preoperative catheter, patients with and without carcinoma of the prostate, patients in whom more or less than $10 \mathrm{~g}$ prostate was resected, and patients with and without a preoperative urinary infection that was unknown at the time. In each case the variables examined were temperature above $38^{\circ} \mathrm{C}$, pulse above $90 / \mathrm{min}$, any appreciable postoperative bacteriuria, and any postoperative complication. Multiple logistic regression analysis showed no evidence that the subgroups of patients differed from one another in respect of cefotaxime efficacy.

Differences did emerge, however, with particular variables. Thus a greater proportion of the subgroup who had a catheter compared 
with those who did not had a pulse rate over $90(\mathrm{p}<0.05)$ and appreciable bacteriuria postoperatively $(p<0.05)$; a greater proportion of the subgroup in whom over $10 \mathrm{~g}$ prostate was resected had a pulse rate of over $90 /$ minute compared with those in whom under $10 \mathrm{~g}$ was resected $(p<0.05)$; and the subgroup with appreciable bacteriuria preoperatively compared with the subgroup with sterile urine preoperatively showed a greater proportion with appreciable bacteriuria postoperatively $(\mathrm{p}<0.001)$. Table $\mathrm{V}$ shows that those with postoperative bacteriuria suffered more complications $(p<0.05)$ but that tachycardia appeared to be unrelated to bacteriuria.

TABLE V-Number ( \%) of patients with complications and tachycardia related to presence of postoperative bacteriuria

\begin{tabular}{lcc}
\hline & Bacteriuria & Sterile urine \\
\hline Cefotaxime & Complications & \\
No treatment & $6(46)$ & $30(28)$ \\
Cefotaxime & Tachycardia & $33(45)$ \\
No treatment & $2(15)$ & $21(19)$ \\
& $18(37)$ & $25(34)$ \\
\hline
\end{tabular}

One case of allergic rash occurred shortly after induction of anaesthesia, in a patient in the no-treatment group. We found no evidence of any deterioration in renal function in the patients who received cefotaxime.

\section{Discussion}

This study confirms and complements results of an earlier study in which cephradine was used. ${ }^{3}$ In both studies the protocols were similar and results showed that patients offered prophylactic antibiotic fare better than patients given no treatment. In the present study the reduction in complications as well as the reduction in postoperative bacteriuria were statistically significant, whereas in the previous study there was only a suggestion of a reduction in complications.

The results showed that prophylactic cefotaxime reduced episodes of fever, tachycardia, the incidence of complications, and the number of days' stay in hospital in all cases, irrespective of whether there had been an unrecognised preoperative urinary infection or the patient had carcinoma of the prostate or had had a preoperative urinary catheter. It is obviously desirable that patients with known preoperative urine infection should be given antibiotics in accordance with results of culture and sensitivity. It is also, however, important to know the effect of any prophylactic regimen as a considerable proportion of patients undergoing prostatic surgery will have urinary infection, though bacterial results may not be known by the surgeon at the time. This is particularly true of patients with a preoperative urinary catheter. It is thus reassuring that prophylaxis administered in the presence of an infection that was unknown at the time was still beneficial.

Although cephalosporins in general and cefotaxime in particular are relatively inactive in vitro against Streptococcus faecalis, in this trial cefotaxime was apparently more effective in preventing postoperative infection with this organism than with Escherichia coli. This may be explained by the antibiotic preventing invasion and establishment of Streptococcus, an organism less capable of doing so than $E$ coli.

It might be argued that we would achieve the same reduction in postoperative bacteriuria and complications by using a topical antibiotic applied as urethral jelly at the time of resection. In our present study the resectoscope was lubricated with $\mathrm{K}-\mathrm{Y}$ Jelly and no topical antibiotic was used. In a recent study of three different antibiotic regimens in patients undergoing prostatic surgery the urethra was anaesthetised with jelly containing chlorhexidine $0.05 \%$ as well as lignocaine. ${ }^{7}$ This study, despite the use of topical antibiotics, confirmed the results of the previous Glasgow study ${ }^{3}$ with respect to reductions in postoperative bacteriuria and complications in patients treated with co-trimoxazole and cephalexin.

Not surprisingly, patients with appreciable bacteriuria postoperatively develop more complications; more surprisingly, perhaps, postoperative tachycardia was not associated with postoperative bacteriuria. In most cases tachycardia occurred within 24 hours after the operation and might be explained by blood or fluid loss; our findings of fewer episodes of tachycardia in the treated patients in the absence of an association with appreciable bacteriuria, however, raises the possibility that the antibiotic may be suppressing episodes of endotoxaemia.

Cefotaxime is a new cephalosporin with a broad spectrum of activity, and this may explain the significant reduction in complications in our study compared with a study using cephradine." This new cephalosporin appears safe in an elderly population. Several reports have suggested the beneficial effects of prophylactic antibiotics in transurethral prostatectomy ${ }^{7}$ but ours is the first to show a statistical reduction in complications in addition to the effect on urinary organisms. On average 1645 prostatectomies are performed each year in Scotland, ${ }^{2}$ and a saving of one inpatient day per patient would, despite the cost of the antibiotic, be of considerable financial benefit.

\section{References}

1 Lytton B, Emery JM, Harvard BM. The incidence of benign prostatic obstruction. 7 Urol $1968 ; 99: 639-45$

2 Graham AG. Scottish prostates : a 6-year review. Brf Urol 1977;49:679-82.

${ }^{3}$ Williams M, Hole DJ, Murdoch RWG, Ogden AC, Hargreave TB. 48Hour cephradine and post-prostatectomy bacteriuria. Br f Urol 1980; 52:311-5.

4 Hamilton-Miller JMT, Brumfitt W, Reynolds AV. Cefotaxime (HR 756), a new cephalosporin with exceptional broad-spectrum activity in vitro. f Antimicrob Chemother 1978;4:437-44.

5 Bax RP. The renal tolerance of cefotaxime. 20th Interscience Conference on Antimicrobial Agents and Chemotherapy. New Orleans, 1980

${ }^{6}$ Mondorf AW, Burk P, Stephanescu T, Scherberich JE, Schoeppe W. Effects of cefotaxime on the proximal tubules of the human kidney. f Antimicrob Chemother 1980;6:155-9.

7 Shah PJR, Williams G, Chaudary M. Short-term antibiotic prophylaxis and prostatectomy. Br $\mathcal{F}$ Urol $1981 ; 53: 339-43$.

${ }^{8}$ Nielsen OS, Maigaard S, Frimodt-Møller N, Madsen PO. Prophylactic antibiotics in transurethral prostatectomy. $\mathcal{F}$ Urol 1981 ;126:60-2.

(Accepted 4 February 1982)

MEDICINES APPROPRIATED TO THE LIVER-Be pleased to take these under the name of Hepatics, for that is the usual name physicians give them, and these also are of three sorts. 1. Some the liver is delighted in. 2. Others strengthen it. 3 . Others help its vices. The palate is the seat of taste, and its office is to judge what food is agreeable to the stomach and what not, by that is both the quality and quantity of food for the stomach discerned: the very same office the meseraik veins perform to the liver. Sometimes such food pleases the palate which the liver likes not (but not often) and therefore the meseraik veins refuse it, and that is the reason some few men fancy such food as makes them sick after the eating thereof. 1 . The liver is delighted exceedingly with sweet things, draws them greedily, and digests them as swiftly, and that is the reason honey is so soon turned into choler. 2. Such medicines strengthen the liver, as (being appropriated to it) very gently bind for seeing the office of the liver is to concoct, it needs some adstriction, that so both the heat and the humour to be concocted may be stayed, that so the one slip not away, nor the other be scattered. Yet do not hepatical medicines require so great a binding faculty as stomachicals do, because the passages of the stomach are more open than those of the liver by which it either takes in chyle, or sends out blood to the rest of the body, therefore medicines that are very binding are hurtful to the liver, and either cause obstructions, or hinder the distribution of the blood, or both. And thus much for the liver, the office of which is to concoct chyle (which is a white substance the stomach digests the food into) into blood, and distributes it, by the veins, to every part of the body, whereby the body is nourished, and decaying flesh restored. (Nicholas Culpeper (1616-54) The Complete Herbal, 1850.) 